\title{
Influence of Quality of Nursing Work Life on Nurses' Turnover Intention: the Mediating Effect of Organizational Commitment
}

\author{
Hyoungshim Choi ${ }^{1}$, Insook Kim² ${ }^{2}$ Yeongyi Yim $^{3}$, Seonae Won ${ }^{4}$ \\ ${ }^{1}$ Assistant Professor, Department of Nursing, Hansei University, Gyeonggi-do, Republic of Korea; ${ }^{2}$ Emeritus \\ Professor, College of Nursing, Yonsei University, Seoul, Republic of Korea; ${ }^{3}$ Director, Department of Health \\ Service Innovation, Korea Industry Development Institute, Chungcheongbuk-do, Republic of Korea, ${ }^{4}$ Assistant \\ Professor, School of Nursing, Taegu Science University, Daegu, Republic of Korea
}

\begin{abstract}
The top priority of this study was to identify how nurses' organizational commitment (OC) serves as a mediating factor between Quality of Nursing Work Life (QNWL) and turnover intention (TI) among Korean nurses. Three hundred thirteen registered nurses working in hospitals participated in this study. Mediating effect analysis was conducted to identify the relationship between QNWL, OC, and TI. The results revealed significant correlations between variables. OC showed a perfect mediating effect in the relationship between QNWL and TI. The results suggest that nurses' QNWL has a significant influence on the TI, which is mediated via OC.
\end{abstract}

Keywords: Nurses, turnover intention, Quality of life

\section{Introduction}

With a continuous increase of the aging population and the number of chronic illnesses every year, hospitals are trying to provide specialized and patient-oriented medical services. ${ }^{1}$ Frequent changes in the medical environment can be a burden to nurses, reducing job satisfaction and increasing the turnover intention, with most countries suffering from a nurse shortage. ${ }^{2-4} \mathrm{~A}$ lack of skilled nursing staff due to high nurse turnover rates leads to overtime work and higher patient-to-nurse ratios, as many patients to be cared for increases. In turn, the quality of medical services is reduced and efforts made on quality improvement and workforce development programs, such as training for new nurses, result in increased health service costs. ${ }^{5}$

\section{Corresponding author: \\ Won, Seonae}

School of Nursing, Taegu Science University, 41453

47 Youngsong-ro, Buk-gu, Daegu, Korea

Tel: +82-53-320-1755 Fax: +82-53-320-1761

Email:wsa1230@gmail.com
The turnover intention is a response to job dissatisfaction and refers to the intention to move from one's current job to a new one; it is a variable that explains the actual turnover behavior. ${ }^{6}$ To manage turnover intention, it is necessary to systematically grasp factors that affect the turnover intention from various perspectives. $^{7}$ Age, position, education level, marital status, working status, career, and salary are factors affecting the turnover intention. ${ }^{8}$ Situational variables include QNWL, OC, job satisfaction, and job stress. ${ }^{9}$

QNWL is a very important factor for employees. In recent years, hospital administrators have been trying to identify and improve the indicators that affect the QNWL in order to prevent the loss of competent nurses. QNWL refers to harmony of work and personal life, including elements required by nurses in order to work satisfactorily in their workplace; therefore, it can be viewed as a reliable and valuable concept that can be used to measure the QNWL of nurses and identify changes that need to be implemented to increase the productivity of the organization. ${ }^{12}$ In general, QNWL was found to affect nurses' job satisfaction and turnover intention. ${ }^{13}$ QNWL and turnover intention have been reported to be negatively correlated, ${ }^{3,9,10}$ while QNWL 
and OC have been reported to be positively correlated. ${ }^{14}$

OC is closely related to how strongly the members trust and agree with the goals and values of the organization, how willing they are to do their best while at the organization, and how earnestly they wish to remain as staff members. ${ }^{15}$ It has been identified as the most influential factor regarding nurses' turnover intention, ${ }^{16}$ and a major attitude variable for nursing staff with a positive influence on organizational effectiveness. ${ }^{17}$

QNWL and OC influence each other, as do OC and the turnover intention. An intermediating effect of emotional OC on the relationship between the QNWL and the turnover intention was found for university professors and other employees. ${ }^{18,19}$ However, no studies have explored the possible intermediating effect of OC on the relationship between QNWL and the turnover intention among nurses. Therefore, this study aimed to identify how nurses' OC serves as a mediator between the QNWL and the turnover intention.

\section{Material and Method}

\section{Study design and sample}

This was a descriptive study aiming to analyze the relationship between QNWL, OC, and the turnover intention and to confirm how nurses' OC serves as an intermediary between the QNWL and the turnover intention.

Three hundred and thirteen general nurses in Seoul and Gyeonggi Province for more than one year participated in this study. Nurses working in general institutions are usually not satisfied with their job during their first year ${ }^{20}$; thus, nurses with less than 12 months of experience were excluded from this study owing to differences in job satisfaction due to length of service. ${ }^{20}$

\section{Ethical Considerations}

This study was approved by the Institutional Ethics Committee of Y University (IRB No. 2014-0061-1). Participants were requested to sign an informed consent form before taking part in the survey.

\section{Measures}

Quality of nursing work life
The Korean version of the QNWL tool ${ }^{21}$ based on Brooks' ${ }^{11}$ QNWL tool was used in this study. This measure has 36 items in four sub-domains. The higher the score, the higher the QNWL. ${ }^{21}$ The internal consistency of the original tool ${ }^{11}$ was $.37-.88$, while the Cronbach's $\alpha$ of the QNWL-K ${ }^{21}$ was .69-.93.

\section{Organizational commitment}

To measure nurses' OC, this study adopted a tool designed by Mowday et al. ${ }^{15}$ and translated by Kim. ${ }^{22}$ This tool includes 15 items. Higher scores reflect higher OC. The reliability of the original instrument measured with Cronbach's $\alpha$ was .82 to .93 , and .89 in the study by Kim. ${ }^{22}$ Cronbach's $\alpha$ in this study was .82 .

\section{Turnover Intention}

We used a modified tool by Park $^{23}$ to measure nurses' turnover intention by adding four questions from the tool used by Lawler. ${ }^{6}$ Lower scores reflect lower turnover intention. Cronbach's $\alpha$ was .88 in the study by Park, ${ }^{23}$ and .85 in the present study.

\section{Data Analysis}

Data were collected over one month from May 1 through 30, 2015. In the final analysis, 313 questionnaires were used.

SPSS 24.0 program was used to analyze the data. T-tests and ANOVA were performed to analyze the differences in variables by nurses' characteristics, and Scheffé's test was performed for post-hoc comparisons. Pearson's correlation coefficient was used to analyze the relationship between QNWL, OC, and turnover intention. Finally, we examined the mediating effect of OC using the procedure of Baron and Kenny, ${ }^{24}$ and verified the significance of the mediation effect with the Sobel test.

\section{Results and Discussions}

\section{Descriptive statistics}

The QNWL of nurses showed a significant difference according to the following general characteristics: marital status ( $t=2.50, p=.013)$, hospital type $(t=5.43$, $p=.005)$. OC showed significance for age $(F=10.87, p$ $<.001)$, education level $(F=10.30, p<.001)$. Turnover Intention showed significant differences for marital 
status $(t=-3.88, p<.001)$, age $(F=10.47, p<.001)$, total clinical career $(F=2.96, p<.033)$. (Table 1$)$.

\section{Correlations between variables}

Significant positive correlations between QNWL and OC $(r=.63, p<.001)$, and between QNWL and nurses' turnover intention $(r=-.43, p<.001)$ were found. (Table 2)
In order to determine the intermediating influence of OC on the relationship between QNWL and turnover intention, the three-step analysis procedure developed by Baron and Kenny ${ }^{24}$ was used (Table 3 ). The Sobel test showed that $\mathrm{OC}$ had served as a significant mediator in the relationship between QNWL and the turnover intention $(Z=-8.07, p<.001$; Figure 1$)$.

Table 1. Differences in Quality of Nursing Work Life, Organizational Commitment, and turnover intention According to Participant Characteristics ( $N=313)$.

\begin{tabular}{|c|c|c|c|c|c|c|c|c|c|}
\hline \multirow{2}{*}{ Characteristics } & \multirow{2}{*}{ Categories } & \multirow{2}{*}{$\mathbf{N}$} & \multirow{2}{*}{$(\%)$} & \multicolumn{2}{|l|}{ QNWL } & \multicolumn{2}{|c|}{$\begin{array}{l}\text { Organizational } \\
\text { commitment }\end{array}$} & \multicolumn{2}{|c|}{ Turnover Intention } \\
\hline & & & & $\mathbf{M} \pm \mathbf{S D}$ & t or F (p) & $\mathbf{M} \pm \mathbf{S D}$ & t or $F(p)$ & $\mathbf{M} \pm \mathbf{S D}$ & $t$ or $F(p)$ \\
\hline Total & & 313 & $(100.0)$ & $3.77 \pm 0.57$ & & $3.02 \pm 0.47$ & & $3.40 \pm 0.82$ & \\
\hline \multirow[t]{2}{*}{ Gender } & Male & 11 & $(3.5)$ & $4.02 \pm 6.61$ & 1.51 & $3.32 \pm 0.62$ & 1.63 & $3.47 \pm 0.88$ & .33 \\
\hline & Female & 302 & $(96.5)$ & $3.76 \pm 0.57$ & $(.133)$ & $3.01 \pm 0.49$ & $(.133)$ & $3.40 \pm 0.82$ & $(.742)$ \\
\hline \multirow[t]{3}{*}{ Age } & $\leq 29 \mathrm{a}$ & 153 & $(48.9)$ & $3.69 \pm 0.53$ & 2.49 & $2.88 \pm 0.39$ & 10.87 & $3.56 \pm 0.75$ & 10.47 \\
\hline & $30-39 b$ & 117 & $(37.4)$ & $3.74 \pm 0.54$ & $(.084)$ & $2.98 \pm 0.45$ & $(<.001)$ & $3.50 \pm 0.78$ & $(<.001)$ \\
\hline & $\geq 40 \mathrm{c}$ & 43 & $(13.7)$ & $3.89 \pm 0.62$ & & $3.22 \pm 0.47$ & $\mathrm{a}, \mathrm{b}<\mathrm{c}$ & $3.03 \pm 0.86$ & $\mathrm{a}>\mathrm{b}, \mathrm{c}$ \\
\hline Education & College (3 years)a & 116 & $(37.1)$ & $3.68 \pm 0.55$ & 2.48 & $2.87 \pm 0.45$ & 10.30 & $3.46 \pm 0.77$ & 1.06 \\
\hline \multirow[t]{2}{*}{ level } & Bachelor (4 years)b & 177 & $(56.5)$ & $3.82 \pm 0.56$ & $(.085)$ & $3.08 \pm 0.46$ & $(<.001)$ & $3.46 \pm 0.77$ & $(.348)$ \\
\hline & Master's degreec & 20 & $(6.4)$ & $3.86 \pm 0.66$ & & $3.31 \pm 0.40$ & & $3.18 \pm 0.89$ & \\
\hline \multirow[t]{2}{*}{ Marital status } & Married & 104 & $(33.2)$ & $3.89 \pm 0.63$ & 2.50 & $3.14 \pm 0.51$ & 2.94 & $3.15 \pm 0.88$ & -3.88 \\
\hline & Single & 209 & $(66.8)$ & $3.71 \pm 0.52$ & $(.013)$ & $2.97 \pm 0.44$ & $(.004)$ & $3.52 \pm 0.76$ & $(<.001)$ \\
\hline \multirow[t]{4}{*}{ Hospital type } & Tertiary & 94 & $(30.0)$ & $3.93 \pm 0.60$ & 5.434 & $3 / 26 \pm 0.43$ & 20.505 & $3.40 \pm 0.91$ & 1.75 \\
\hline & General & 154 & $(49.2)$ & $3.69 \pm 0.53$ & $(.005)$ & $2.90 \pm 0.44$ & $(<.001)$ & $3.46 \pm 0.75$ & $(.176)$ \\
\hline & Hospital with less & 65 & $(20.8)$ & $3.74 \pm 0.55$ & & $2.96 \pm 0.47$ & & $3.24 \pm 0.82$ & \\
\hline & beds $\quad$ than 300 & & & & & & & & \\
\hline Total clinical & $1-3 \mathrm{a}$ & 60 & $(19.2)$ & $3.79 \pm 0.49$ & .70 & $3.06 \pm 0.37$ & 3.63 & $3.46 \pm 0.79$ & 2.96 \\
\hline experience & $3-5 b$ & 61 & (19.5) & $3.68 \pm 0.59$ & $(.168)$ & $2.90 \pm 0.47$ & $(.013)$ & $3.61 \pm 0.77$ & $(.033)$ \\
\hline \multirow[t]{2}{*}{ (years) } & $5-10 c$ & 98 & (31.3) & $3.72 \pm 0.57$ & & $2.97 \pm 0.47$ & $b<d$ & $3.39 \pm 0.79$ & $b>d$ \\
\hline & $\geq 10 \mathrm{~d}$ & 94 & $(30.0)$ & $3.87 \pm 0.57$ & & $3.13 \pm 0.50$ & & $3.23 \pm 0.87$ & \\
\hline \multirow[t]{3}{*}{ Salarya } & $<30 \mathrm{a}$ & 120 & $(38.3)$ & $3.62 \pm 0.53$ & 7.66 & $2.88 \pm 0.44$ & 20.66 & $3.43 \pm 0.77$ & 9.79 \\
\hline & $30-50 \mathrm{~b}$ & 155 & $(49.5)$ & $3.83 \pm 0.54$ & $(.001)$ & $3.04 \pm 0.42$ & $(<.001)$ & $3.50 \pm 0.76$ & $(<.001)$ \\
\hline & $\geq 50 \mathrm{c}$ & 38 & (12.1) & $3.97 \pm 0.69$ & $\mathrm{a}, \mathrm{b}<\mathrm{c}$ & $3.40 \pm 0.52$ & $\mathrm{a}, \mathrm{b}<\mathrm{c}$ & $2.87 \pm 0.97$ & $\mathrm{~b}>\mathrm{a}, \mathrm{c}$ \\
\hline \multirow[t]{2}{*}{ Children } & Without children & 228 & $(72.8)$ & $3.71 \pm 0.54$ & -2.88 & $2.97 \pm 0.45$ & -2.90 & $3.51 \pm 0.79$ & 3.90 \\
\hline & Children & 85 & $(27.2)$ & $3.92 \pm 0.61$ & $(.004)$ & $3.14 \pm 0.48$ & $(.004)$ & $3.11 \pm 0.83$ & $(<.001)$ \\
\hline
\end{tabular}

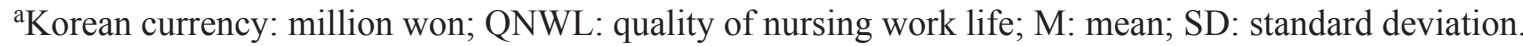


Table 2. Correlational Relationships between QNWL, Organizational Commitment, and Turnover Intention $(\mathbf{N}=\mathbf{3 1 3})$.

\begin{tabular}{|c|c|c|c|}
\hline Variables & QNWL & $\begin{array}{l}\text { Organizational } \\
\text { commitment }\end{array}$ & Turnover Intention \\
\hline & $r(p)$ & $\mathbf{r}(\mathbf{p})$ & $r(p)$ \\
\hline QNWL & 1 & $.63(<.001)$ & $-.43(<.001)$ \\
\hline $\begin{array}{l}\text { Organizational } \\
\text { commitment }\end{array}$ & & 1 & $-.61(<.001)$ \\
\hline Turnover intention & & & 1 \\
\hline
\end{tabular}

Table 3. Mediating Effect of Organizational Commitment on the Relationship between QNWL and Turnover Intention $(\mathrm{N}=313)$.

\begin{tabular}{|l|l|l|l|l|l|l|l|}
\hline Equations & B & $\boldsymbol{\beta}$ & T & $\mathbf{p}$ & Adj.r2 & F & p \\
\hline 1. QNWL $\rightarrow$ OC & 0.22 & 0.627 & 14.18 & $<.001$ & 0.39 & 201.05 \\
\hline 2. QNWL $\rightarrow$ TI & 0.07 & 0.43 & 8.43 & $<.001$ & 0.18 & 71.02 & $<.001$ \\
\hline 3. QNWL, OC $\rightarrow$ TI & & & & & 0.38 & 95.11 & $<.001$ \\
\hline 4. QNWL $\rightarrow$ TI & 0.01 & 0.08 & 1.34 & .182 & & $<.001$ \\
\hline 5. OC $\rightarrow$ TI & 0.26 & 0.57 & 9.86 & $<.001$ & 0.38 & 187.96 & $<.001$ \\
\hline
\end{tabular}

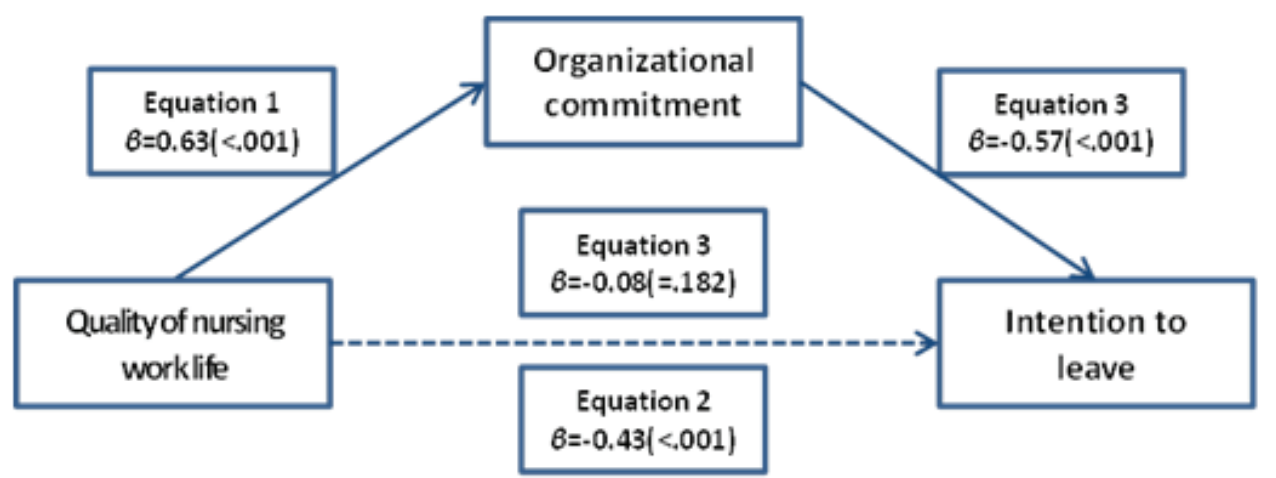

Figure 1. Model showing the Influence of Quality of Nursing Work Life on the Turnover Intention and the Mediating Effect of Organizational Commitment.

\section{Discussion}

The average score of turnover intention was 3.4 out of 4.00. This is relatively high compared to the turnover intention score of 2.96 found among nurses in smallsized hospitals obtained using the same tool by Hwang and Kang. ${ }^{7}$ The general characteristics that showed a difference in turnover intention were age, marital status, children, and clinical career. Turnover intention was higher for those aged below 29, single, without children, and with clinical experience between 3-5 years and a higher salary. These results were supported by a previous study. ${ }^{25}$ Nurses with clinical careers of 3-5 years tend to perceive their work as repetitive rather than experiencing 
increased confidence. Therefore, differentiated policies and efforts are needed to lower the turnover intention among nurses.

In this study, there were statistically significant correlations between QNWL, OC, and the turnover intention. QNWL and OC showed a very strong positive correlation. Additionally, QNWL and the turnover intention were negatively correlated, as previously noted. ${ }^{9,27} \mathrm{OC}$ and the turnover intention showed a strong negative correlation, which adds to the body of literature suggesting that $\mathrm{OC}$ is the strongest correlated factor among those negatively correlated with the turnover intention. $^{7}$

Our results showed that OC functioned as a significant mediator between QNWL and the turnover intention. This implies that $\mathrm{OC}$ is a critical factor in the relationship between QNWL and the turnover intention. OC can be increased by increasing QNWL, and the turnover intention can be decreased by increasing OC. In addition to the demonstrated mediating effects of OC in relation to nurses' perceptions of work environment and turnover intention. ${ }^{1}$ This study confirmed the full mediating effect of OC between QNWL and the turnover intention. Therefore, hospital administrators need to understand the relationships between these variables in order to reduce nurses' turnover rates. Career development courses are needed to improve the relationship between multidisciplinary teams working together in hospitals, and customized welfare system should be strengthened in order to increase QNWL. Furthermore, employee management strategies that reflect the existing hospital system should be developed to enhance the overall QNWL, toward the aim of fostering a healthy work/life balance for nurses. ${ }^{19,27}$

This study has several significant implications. First, we confirmed the degree of QNWL of Korean nurses, which is an important concept for enhancing organizational productivity through the harmonization of work and personal life. Second, by analyzing the intermediating influence of $\mathrm{OC}$ in the relationship between QNWL and turnover intention, which is closely related to the quality and cost of medical services, we deepened our understanding of the turnover intention and provided basic data for the development of interventions. Third, by using the QNWL-K based on
Brooks' ${ }^{11}$ QNWL tool, which is widely used in Asian countries comparisons of the same items are made possible. However, since this study was conducted with nurses working in hospitals in Seoul and its metropolitan area, there is a limitation to the generalizability of the results.

\section{Conclusion}

The findings of this study revealed that QNWL and $\mathrm{OC}$ were positively correlated, whereas $\mathrm{OC}$ and turnover intention were negatively correlated. OC was also found to fully mediate the relationship between QNWL and the turnover intention. Therefore, policies and organizational efforts to raise QNWL should be developed to increase OC.

Since this study examined the relationship between QNWL, OC, and the turnover intention, we propose further empirical studies to identify the factors affecting QNWL, which will be useful for the development of intervention programs for improving it. Additionally, we propose a follow-up study to identify QNWL levels and influential factors for nurses working in various fields as well as hospitals.

Ethical Clearance: Approved

\section{Source of Funding: Self}

\section{Conflict of Interest: Nil}

\section{References}

[1] Seok HS. Factors affecting organizational commitment and turnover intention of hospital nurses: focused on the mediating effects of person-environment fit. J Korean Acad Nurs Adm. 2013;19(3):361-371. https://doi.org/10.11111/ jkana.2013.19.3.361

[2] Lee YW, Dai YT, Chang MY, Chang YC, Yao KG, Liu MC. Quality of work life, nurses' intention to leave the profession, and nurses leaving the profession: a one-year prospective survey. J Nurs Scholarsh. 2017;49(4):438-444. http://doi.org/10.1111/jnu.12301.

[3] Aiken LH, Sermeus W, Van den Heede K, Sloane DM, Busse R, McKee M, Bruyneel L, Rafferty AM, Griffiths P, Moreno-Casbas MT, Tishelman C. Patient safety, satisfaction, and quality of hospital care: cross sectional surveys of nurses 
and patients in 12 countries in Europe and the United States. BMJ. 2012;344:e1717. https://doi. org/10.1136/bmj.e1717

[4] Buerhaus PI, Auerbach DI, Staiger DO. The recent surge in nurse employment: causes and implications. Health Aff. 2009;28(4):w657-w668. http://doi.org/10.1377/hlthaff.28.4.w657

[5] Jones CB. The costs of nursing turnover, part I: an economic perspective. J Nurs Adm. 2004;34(12):562-570. https://doi. org/10.1097/00005110-200412000-00006

[6] Lawler EE. Satisfaction and behavior. Motivation and work behavior 332. New York, NY: McGraw Hill; 1983.

[7] Hwang YS, Kang KH. Factors influencing nurse turnover intention in small and medium sized hospitals in the metropolitan area. J Korean Acad Nurs Adm. 2014;20(5):576-586. https://doi. org/10.11111/jkana.2014.20.5.576.

[8] Kim JK, Kim MJ. A review of research on hospital nurses' turnover intention. J Korean Acad Nurs Adm. 2011;17:538-550. https://doi. org/10.11111/jkana.2011.17.4.538

[9] Lee YW, Dai YT, Chang MY, Chang YC, Yao KG, Liu MC. Quality of work life, nurses' intention to leave the profession, and nurses leaving the profession: a one-year prospective survey. J Nurs Scholarsh. 2017;49(4):438-444. http://doi.org/10.1111/jnu.12301.

[10] Faraji O, Salehnejad G, Gahramani S, Valiee $\mathrm{S}$. The relation between nurses' quality of work life with intention to leave their job. Nurs Pract Today. 2017;4(2):103-111. Available from http:// npt.tums.ac.ir/index.php/npt/article/view/236

[11] Brooks BA. Development of an instrument to measure quality of nursing work life [dissertation]. Chicago; University of Illinois at Chicago; 2002. Available from UIC Library at https://indigo.uic. edu/handle/10027/11732.

[12] Brooks BA, Anderson MA. Defining quality of nursing work life. Nurs Econ. 2005;23(6):319326.

[13] Huang TC, Lawler J, Lei CY. The effects of quality of work life on commitment and turnover intention. Soc Behav Pers. 2007;35(6):735-750. https://doi.org/10.2224/sbp.2007.35.6.735

[14] Gellatly IR, Cowden TL, Cummings GG. Staff nurse commitment, work relationships, and turnover intentions: a latent profile analysis. Nurs Res. 2014;63:170-181. http://doi.org/10.1097/ NNR.0000000000000035

[15] Mowday RT, Steer RM, Porter LW. The measurement of organizational commitment. J Vocat Beh. 1979;14(2):224-247. https://doi. org/10.1016/0001-8791(79)90072-1

[16] Jeong JH, Kim JS, Kim KH. The risk factors influencing turnover intention of nurses. J Korean Acad Nurs Adm. 2008;14(1):35-44. Available from http://www.koreascience.or.kr/article/ JAKO200828835718583.page

[17] Sabarirajan A, Geethanjali NA. Study on quality of work life and organizational performance among the employees of public and private banks in Dindigul. Int J Econ Res. 2011;2:3845. Available from http://www.oalib.com/ paper/2066297\#.XP2O2-RYeuU

[18] Kamel MM. The mediating role of affective commitment in the relationship between quality of work life and intention to leave. Life Sci J. 2013;10(4):1062-1067. Available from http:// www.lifesciencesite.com/lsj/life1004/138_21282 life1004_1062_1067.pdf

[19] Yusoff YM, Rimi NN, Meng CH. A study of quality of work life, organizational commitment and turnover intention. Probl Perspect Manag. 2015;13(2):357-364. Available from https://businessperspectives.org/images/pdf/ applications/publishing/templates/article/ assets/6751/PPM_2015_02spec.issue_M Yusoff.pdf

[20] McCloskey JC, McCain BE. Satisfaction, commitment and professionalism of newly employed nurses. Image $J$ Nurs Sch. 1987;19(1):20-24.

[21] Kim IS, Choi HS, Yim YY, Won SA, Kim JW, Lee SA. Quality of nursing work life scale-Korean: validity and reliability. Korean J Adult Nurs. 2016;28(6):646-658. http://doi. org $/ 10.7475 / \mathrm{kjan} .2016 .28 .6 .646$

[22] Kim JJ. (The) empirical study on the turnover decision process research scientist: replication unfolding model [dissertation]. Seoul, Korea: Korea University; 2002. Available from http://www.riss.kr/search/detail/DetailView. do?p_mat_type $=$ be $54 d 9 b 8 b c 7 c d b 09 \&$ control_ no $=69 \mathrm{fa} 4090 \mathrm{e} 20 \mathrm{de} 12 \mathrm{~d}$ 
[23] Park HS. Relationship between perceived nursing care role orientation, job characteristics, and turnover among nurses [dissertation]. Seoul, Korea: Yonsei University; 2002. Available from http://www.riss.kr/link?id=T8371025

[24] Baron RM, Kenny DA. The moderator-mediator variable distinction in social psychological research: conceptual, strategic, and statistical considerations. J Pers Soc Psychol. 1986;51:11731182.

[25] Fu X, Xu J, Song L, Li H, Wang J, Wu X, Li H, Wang J, Wu X, Hu Y, Wei L, Gao L, Wang Q, Lin Z. Validation of the Chinese version of the quality of nursing work life scale. PloS One. 2015;10(5):e0121150. http://doi.org/10.1371/ journal.pone. 0121150

[26] Sirin M, Sokmen SM. Quality of nursing work life scale: the psychometric evaluation of the Turkish version. Int $\mathrm{J}$ Caring Sci. 2015;8(3):543-554. Available from https://pdfs.semanticscholar.org/8f03/ c558a146ba7dba42136a3f8bfab79d57a23d.pdf

[27] Almalki MJ, FitzGerald G, Clark M. Quality of work life among primary health care nurses in the Jazan region, Saudi Arabia: a cross-sectional study. Hum Resour Health. 2012;10(1):1-13. http://doi.org/10.1186/1478-4491-10-30. 